\title{
Pengembangan Sistem Stock Opname Berbasis Mobile Application Using SDLC Methode
}

\author{
Masmur Tarigan \\ Fakultas Ilmu Komputer \\ Universitas Esa Unggul \\ Jakarta, Indonesia \\ masmur.tarigan@esaunggul.ac.id
}

\begin{abstract}
Stock taking in a company is important. However, there are often problems when the stock taking process is running, such as frequent loss of connection between the scanner and the tab, thereby reducing work productivity. The implementation of a stock-taking system that has not used a mobile apps-based system has an effect on productivity, speed and effectiveness in the process. The purpose of making this application is to make it easier for officers in the stock-taking process because the mobile apps system uses only one smart device that makes it easier for users to input stock data quickly so as to increase productivity, speed and effectiveness. The method used in making the application is SDLC (System Development Life Cycle) Waterfall, and continued by modeling the design of the mobile apps system with UML (Unified Modeling Language). To test the application and ensure that the application runs well, a trial will be carried out with black box method This mobile appbased stock taking system is used to further optimize work productivity as well as cut equipment operating costs. Based on testing the black box method, this application runs well and is in accordance with its function
\end{abstract}

Keywords- mobile application; stock opname: qr code: SDLC: black box: UML

Abstrak- Stock opname dalam sebuah perusahaan merupakan hal yang penting. Namun sering terjadi kendala saat proses stock opname berjalan, seperti sering loss connection antara scanner dengan tab sehingga mengurangi produktivitas pekerjaan. Pengimplementasian sistem stock opname yang belum menggunakan sistem berbasis mobile apps berpengaruh terhadap produktivitas, kecepatan dan keefektifan dalam prosesnya. Tujuan pembuatan aplikasi ini adalah untuk mempermudah petugas dalam proses stock opname karena sistem mobile apps cukup menggunakan satu perangkat cerdas yang mempermudah user dalam menginput data stock dengan cepat sehingga meningkatkan produktivitas, kecepatan dan keefektifan. Metode yang digunakan dalam membuat plikasi adalah SDLC (System Development Life Cycle) Waterfall, dan dilanjutkan dengan membuat pemodelan rancangan sistem mobile apps dengan UML (Unified Modelling Language).untuk uji coba aplikasi dan memastikan bahwa aplikasi berjalan dengan baik, maka akan dilakukan ujicoba dengan metode black box Sistem stock opname berbasis mobile apps ini digunakan untuk lebih mengoptimalkan produktivitas pekerjaan juga memangkas biaya operasional alat. Berdasarkan pengujian metode black box, aplikasi ini berjalan dengan baik dan sesuai dengan fungsinya

Keywords - aplikasi mobile; stok opname; qr code; SDLC; black box; UML

\section{PENDAHULUAN}

Stock opname ialah kegiatan yang berkaitan dengan penghitungan persediaan barang bertujuan mencocokan antara jumlah real barang dengan jumlah yang ada pada stok laporan [1]. Stock opname memiliki peran yang penting yaitu; meminimalisir selisih yang ada pada jumlah barang yang bertujuan bertindak dengan lebih cepat jika ada selisih, atau ada barang yang hilang sehingga mencegah terjadinya kekosongan barang. Laporan dari stok opname ini juga dapat dijadikan analisa dalam mengetahui perkembangan perusahaan dilihat dari masuk dan keluar barang yang ada di gudang secara pasti [2].

Kegiatan stok opname tidak hanya dilakukan oleh bidang industry saja, bidang usaha lain juga menerapkan stok opname guna memantau dan mengontrol material dan produk mereka, beberapa artikel membahas tentang stok opname yang dilakukan di rumah sakit, perpustakaan, retail dan masih banyak lagi [6]-[10]. Hal ini menunjukan kegiatan stok opname bagi bidang industry maupun non industry sangat penting untuk dapat memantau ketersediaan.

Sekarang ini teknologi berkembang seiring dengan kebutuhan, teknologi banyak membantu pekerjaan manuasia menjadi lebih mudah dan cepat. Tidak terkecuali kegiatan di dalam bidang industry, seiring waktu teknologi yang digunakan juga mengalami pembaharuan, seperti hal nya yang terjadi di PT. Modern Gravure Indonesia, yang terus memperbaharui system guna menunjang kegiatan di dalamnya. Kegiatan stok opname di PT. Modern Gravure Indonesia membutuhkan fasilitas system yang dapat bekerja lebih efektif dan sederhana di banding dengan system yang saat ini berjalan.

Kegiatan stok opname di PT. Modern Gravure Indonesia dilaksanakan setiap bulan pada minggu terakhir. Kegiatan stok opname yang berjalan di PT. Modern Gravure Indonesia saat ini menggunakan sistem scan qr barcode dengan media pembacaan kode qr code yang terhubung dengan tab sebagai media untuk mengakses ke dalam sistem itu sendiri. Pelaksanaan stock opname dilakukan oleh beberapa orang khusus yang terdiri dari department produksi, accounting, dan warehouse yang dibagi dalam team untuk dikerjakan berdasarkan pembagian wilayah stock opname. Satu team terdiri dari 2-3 orang yang berperan sebagai user yang memindai data qr code melalui scanner dan yang lain memeriksa pengecekan barang atau meterialnya. Dari latar belakang yang telah dijabarkan, PT. Modern Gravure Indonesia memiliki beberapa permasalahan sebagai berikut:

Pertama, perusahaan belum memiliki sistem yang dapat membuat pekerjaan stock opname menjadi lebih praktis, 
lebih flexible dan lebih cepat. Dimana saat pelaksanaan stock opname ini mengharuskan menggunakan beberapa media seperti tab dan scanner qr code yang dihubungkan menggunakan kabel, selain itu sering terjadinya masalah koneksi terputus antara kabel scanner qr code dengan tab yang jika digunakan pemakaian secara terus menerus akan menimbulkan masalah longgar pada konektor yang ada pada tab.

Kedua, masih menggunakan lebih banyak media alat dan lebih banyak orang dalam proses stock opname. Pada saat proses memindai qr code ini mengalami keterbatasan kabel penghubung antara scanner dengan tab sehingga kurang praktis dalam proses stok opname jika dilakukan di warehouse raw material yang memiliki banyak barang yang di susun, sehingga beberapa kali kabel penghubung tersebut tersangkut atau tersenggol yang mengakibatkan putus koneksi antara scanner dan tab dan memakan waktu yang relative lebih lama karena masalah-masalah tersebut.

Ketiga, belum adanya pengembangan sistem berbasis mobile apps.

Tujuan dan manfaat bagi perusahaan dalam penelitian ini yaitu membuat sistem stok opname berbasis android sebagai fasilitas pendukung kegiatan stok opname di PT. Modern Gravure Indonesia untuk mendapatkan data stok dengan waktu yang relative cepat, praktis dan menghindari masalahmasalah yang tidak di inginkan. Memudahkan tim yang bertugas dalam kegiatan stok opname yang diadakan setiap bulan dalam prosesnya. Serta menggunakan teknologi yang lebih update dari scan qr code menggunakan scanner.

Agar aplikasi yang akan dibangun dapat mencakup berbagai perangkat yang akan digunakan oleh user atau pengguna dan tetap memiliki fungsionalitas yang sama, maka perlu menggunakan Web Responsive aplikasi ini juga menggunakan tampilan Bootstrap front end framework untuk membangun desain web yang responsive.

Jurnal oleh Muhammad Fahruddin Yusuf yang berjudul Pembuatan Aplikasi Mobile Berbasis Android Sebagai Penunjang Kinerja Sales \& Warehouse di PT. Masuya Distra Sentosa jurnal ini membahas tentang ketersediaan jumlah persediaan, informasi mengenai barang yang tersedia, nilai minimum penjualan dari barang, riwayat penjualan, juga informasi lain yang diperlukan saat proses pembuatan sales order pada saat marketing sedang berada di customer. Untuk menangani permasalahan tersebut, maka perlu dilakukan develop sistem berbasis mobile apps android sebagai fasilitas pendukung kinerja bagian marketing dan bagian warehouse [3]. Perbandingannya antara jurnal Muhammad Fahruddin Yusuf dengan jurnal ini adalah walaupun sama-sama membahas tentang pengembangan system yang lama menjadi aplikasi mobile namun scope penelitian berbeda karna aplikasi yang dikembangkan berbeda bukan hanya dapat melihat ketersediaan stok barang saja, tapi aplikasi ini dikhususkan dapat membantu menunjang kinerja petugas dalam kegiatan stok opname sehingga pekerjaan lebih efektif dan efisien dari system yang sebelumnya.

Artikel ilmiah ini berjudul Perancangan Aplikasi Stock Opname Asset Berbasis Web dan Android (Studi Kasus : PT Indomarco Prismatama. Jurnal ini membahas tentang aplikasi mobile yang menyediakan fasilitas untuk pencarian berdasarkan dari nama barang, sehingga pada saat akan dilakukan pengecekan akan mengefisiensi waktu karena dapat dilakukan dengan waktu yang relative lebih cepat walaupun jumlah data dari barang itu banyak. [4]. Perbandingan antara artikel ilmiah karya Mesah Tuahta Barus DKK dengan penelitian ini adalah dari fungsional aplikasi mobile, dimana penelitian ini membahas aplikasi mobile untuk stok opname dan memberikan fitur yang dapat melihat jumlah stok barang dan detail dari barang tersebut, juga dapat melakukan pencarian berdasarkan nama barang dan juga nomor lotnya.

Jurnal Pengembangan Sistem Informasi Perpustakaan Menggunakan Teknologi Google Web Toolkit (GWT) dalam jurnal ini mengandung pembahasan tentang aplikasi mobile yang terintegrasi dengan Senayan Library Management System (SLiMS). Aplikasi mobile yang dibuat ini mengefisiensi waktu dengan melakukan penghematan waktu kegiatan stock opname yang sebelumnya dilakukan dengan tiga langkah kemudian dengan adanya system yang baru mempersingkat menjadi satu langkah saja, sehingga waktu yang dibutuhkan berkurang hingga 50\% [5]. Perbandingannya antara jurnal yang diteliti oleh Pradani DKK dengan jurnal ini adalah fungsionalitas dari aplikasi mobile jika jurnal yang dibahas oleh Pradani DKK tentang integrase web SLiMS dengan teknologi GWT, maka jurnal ini membahas aplikasi mobile yang menggunakan Flutter Framework sehingga dapat dijalankan di dua platform android dan iOS dan cara stok opname yang dikerjakannyapun berbeda, aplikasi stok opname MGI ini menggunakan bardcode sebagai penyimpan data dari barang yang akan dipindai oleh aplikasi kemudian data yang ada dalam barcode akan disimpan kedalam data base.

\section{METODE PENELITIAN}

\section{A. Metode SDLC (System Development Life Cycle) Waterfall \\ Dalam pembuatan aplikasi ini, dibutuhkan metode yang} tujuannya untuk menyelesaikan masalah dengan cara yag efektif, untuk itu pengembangan system ini menggunakan model yang air terjun atau biasa disebut waterfall. Pada penelitian ini menggunakan metode SDLC karena memiliki persyaratan yang jelas yang tidak akan berubah sepanjang siklus hidup proyek. Dapat dilihat pada gambar berikut:

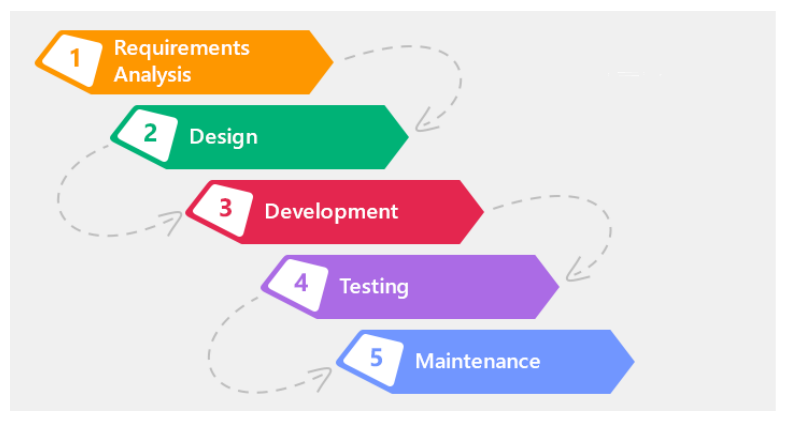

Gambar 1. Metode SDLC Waterfall [11]

Requirement gathering and analysis yaitu langkah identifikasi kebutuhan yang global. Kemudian dilanjutkan dengan analisis kebutuhan yang kelak akan dipenuhi oleh program atau sistem yang akan kembangkan. Pada tahap ini untuk menghasilkan desain yang baikm maka tahp ini harus dikerjakan dengan lengkap. 
Tahap desain. System yang baik harus menetapkan runtut, software, sampai algoritma yang rinci dan hal ini harus dilakukan oleh pengembang.

Tahap implementasi. pada bagian ini semua desain sudah di buat lebih dahulu akan digantikan oleh kode-kode program . Kode progam ini selanjutnya akan diintegrasikan lagi sehingga membentuk sistem yang komplet.

Tahap integration and testing, pada bagian ini pengembang melakukan inetgrasi terhadap modul-modul yang sebelumnya telah dibuat untuk percobaan yang tujuannya adalah mengecek terkait aplikasi sseudah berfungsi sesuai dengan harapan dan mengecek kembali jika ada kesalahan.

Verifikasi, pada bagian ini user akan melakukan pengujian aplikasi atau system apakah sudah sesuai atau belum.

Operation and maintenance yaitu tahap pemasangan dan tahap proses utnuk dilakukan perbaikan pada sistem apakah sudah sesuai dengan yang disepakati [11].

\section{B. Analisis masalah dengan metode fishbond}

Untuk menganalisis masalah menggunakan metode fishbond. Diagram ini juga disibut Ishikawa yaitu diagram sebab akibat [12]. Gambar diagram fishbond dapat dilihat pada gambar 2 .

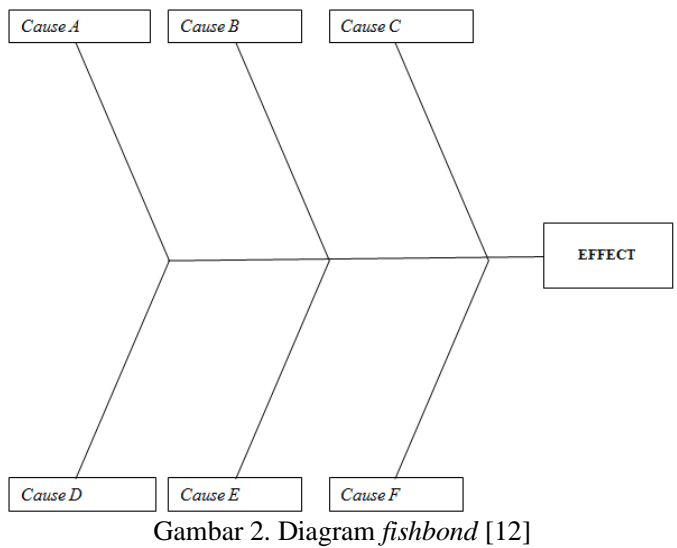

Pada tahapan ini, didapatkan masalah yang dikelompokan yang dihasilkan pada proses diskusi dengan stakeholder. Hasil dari analisa masalah dapat dilihat di tabel I.

TABEL I. ANALISIS MASALAH

\begin{tabular}{|c|c|c|}
\hline \multirow{2}{*}{ Faktor } & Nomor & Hasil Analisis \\
\hline \multirow{2}{*}{ Data } & 1 & $\begin{array}{c}\text { Data stok opname yang diterima relative } \\
\text { kurang cepat }\end{array}$ \\
\cline { 2 - 3 } & 2 & $\begin{array}{c}\text { Laporan data stok opname mengalami } \\
\text { keterlambatan }\end{array}$ \\
\hline \multirow{2}{*}{ Man } & 3 & $\begin{array}{c}\text { Membutuhkan banyak petugas dalam tim } \\
\text { stok opname per-area }\end{array}$ \\
\cline { 2 - 3 } & 4 & $\begin{array}{c}\text { Terbatasnya petugas yang melakukan stok } \\
\text { opnamet }\end{array}$ \\
\hline \multirow{2}{*}{ Tools } & 5 & Belum adanya sistem berbasis android \\
\hline
\end{tabular}

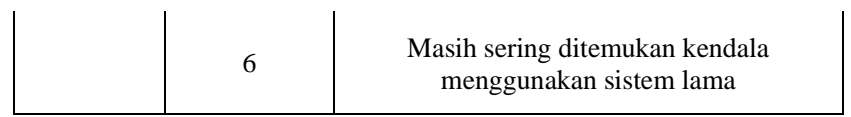

\section{Pemodelan dengan UML}

Dalam perancangan sistem dibutuhkan pemodelan untuk merepresentasikan rancangan sistem informasi yang akan dibuat ehingga menjadi sebuah sistem informasi yang siap digunakan oleh user, maka Unified Modelling Language (UML) dijadikan metode pemodelannya.

UML memiliki fungsi untuk memenuhi pembuatan analisis dan rancangan, dengan menjelaskan rancangan dalam bentuk pemrograman berorientasi objek UML juga menggunakan standar bahasa yang banyak dipakai lingkup industri untuk mendefinisikan requirement, [8].

\section{Pengumpulan Data}

Pengumpulan data dilakukan dengan cara survey dan wawancara, penelitian dilakukan secara langsung di PT. Modern Gravure Indonesia

Berdasarkan hasil wawancara yang dilakukan di PT. Modern Gravure Indonesia sebagai berikut :

1) Belum adanya sistem stock opname berbasis mobile apps.

2) Masih menggunakan sistem scan $q r$ code yang mengharuskan menggunakan 2 alat yaitu tab dan scanner $q r$ code yang kurang praktis dibanding menggunakan mobile apps.

3) Sering terjadinya loss connection antara kabel scanner dengan konektor pada $t a b$ akibat dari penggunaan yang terlalu sering, sehingga bisa menghambat proses scanning qr code pada stock opname.

4) Membutuhkan lebih banyak anggota pada tim saat melakukan stock opname

\section{E. Analisis Sistem}

Dalam membangun sistem ini, beberapa kebutuhan harus dipersiapkan, diantaranya :

1) Kebutuhan fungsional antara lain ;

a. Dapat menampilkan menu utama, sistem mampu memberikan informasi yang baik dan akurat agar mendapatkan hasil yang maksimal,

b. Sistem mampu membaca $Q r$ code dengan waktu yang relatif lebih singkat sehingga menghemat waktu dan memaksimalkan produktivitas dalam pekerjaan,

c. Mampu membuat pengguna mengerti dan memahami cara penggunaan sistem stock opname berbasis mobile.

2) Kebutuhan non-fungsional yang meliputi

a. Kebutuhan software yaitu sistem operasi windows 10 64-bit, Bahasa pemrograman yang digunakan Java Development Kit (JDK) dan Java Runtime Environment (JRE), Android Software Development Kit (Android SDK), Integrated Development Environment (IDE) Eclipse, Development Tools, Android Development Tools (ADT)

b. Kebutuhan hardware yaitu perangkat $P C$ dengan ketentuan processor : Intel (R) Core (TM) i5-4200M CPU @ 2.50GHz 


\section{F. Flutter Framework}

(4CPUs), 2.5 GHz, Memory : $4096 \mathrm{MB}$ RAM, HDD 1 Terabyte, VGA : NVIDIA GeForce GT 740M. sedangkan perangkat android-nya yaitu smartphone dengan sistem operasi minimal v4.1.2 Jelly Bean, CPU Dual-core $1.5 \mathrm{GHz}$ Krait

Dalam pembuatan aplikasi stok opname MGI berbasis mobile ini, membutuhkan framework. Framework. yang digunakan untuk membuat aplikasi mobile pada sistem stock opname MGI berbasis mobile adalah Flutter framework. Dimana flutter yang dikembangkan oleh Google ini adalah suatu SDK yang fungsinya sebagai pengembangan system aplikasi mobile dan membangun aplikasi yang mempunyai performa yang juga bisa dipublikasikan ke dalam platform Android dan iOS dari basis kode tunggal [13].

Flutter juga bisa dipelajari dengan mudah. Bahasa yang digunakan adalah Dart yang sudah familiar bagi pengguna Bahasa java. selanjutnya flutter juga melibatkan kerangka reaktif fungsional, mesin render $2 \mathrm{D}$, widget siap pakai, juga alat untuk development [13].

\section{G. JSON Web Token (JWT)}

Dalam aplikasi mobile stock opname ini, create API yang diguakan menggunakan bahasa python dengan library JWT. JWT sendiri yaitu token yang bentuknya string JWT memiliki bebrapa bagian yaitu : header, payload dan signature, yang fungsinya untuk memproses verifikasi dan pergantian data [14]. Token ini sendiri terdiri dari dua jenis yaitu : pertama token pembawa dan yang kedua token pemegang kunci. Bersumber pada tujuannya, ada dua skema yang pertama token identitas dan kedua token akses [15].

Cara kerja JWT sendiri mirip dengan password, dimana saat user berhasil login maka server tersebut akan mengirimkan token yang terdapat di penyimpanan lokal atau cookies browser. Token sendiri dipakai bagi user dalam masuk ke halaman tertentu, setelah pengguna menerima token, maka pengguna akan mengirimkan kembali token tersebut untuk memvalidasi pengguna bahwa sudah sukses untuk login [16].

Berikut ini beberapa karakteristik dari JWT:

a. Header, contohnya seperti HMAC SHA256 atau $R S A$, header sendiri berisi dua bagian, yang pertama jenis token, JWT, dan yang kedua adalah algoritma hashing

b. Payload. ialah bagian selanjutnya dari token yang menyimpan klaim. Pertanyaan yang berkaitan dengan entitas itu disebut dengan klaim dan dapat berupa metadata yaitu reserved, public, dan private.

c. Signature. Difungsikan sebagai tandatangan yang dikodekan di header.

d. Signature ini fungsinya sebagai verifikator yang bertugas memastikan jika ia sebagai pengirim yang valid dan untuk membuktikan jika pesan tidak di ubah.

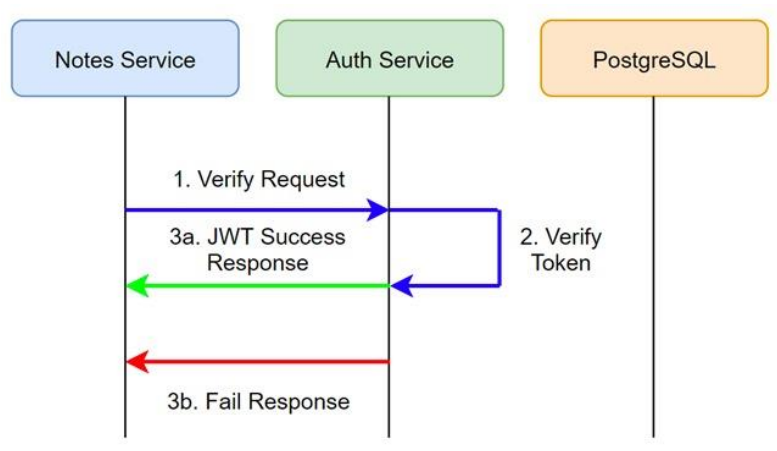

Gambar 4. Sistem Verifikasi Token API

Contoh payload response yang didapatkan dan ditampilkan oleh front-end : pada table II.

TABEL II. JSON RESPONSE

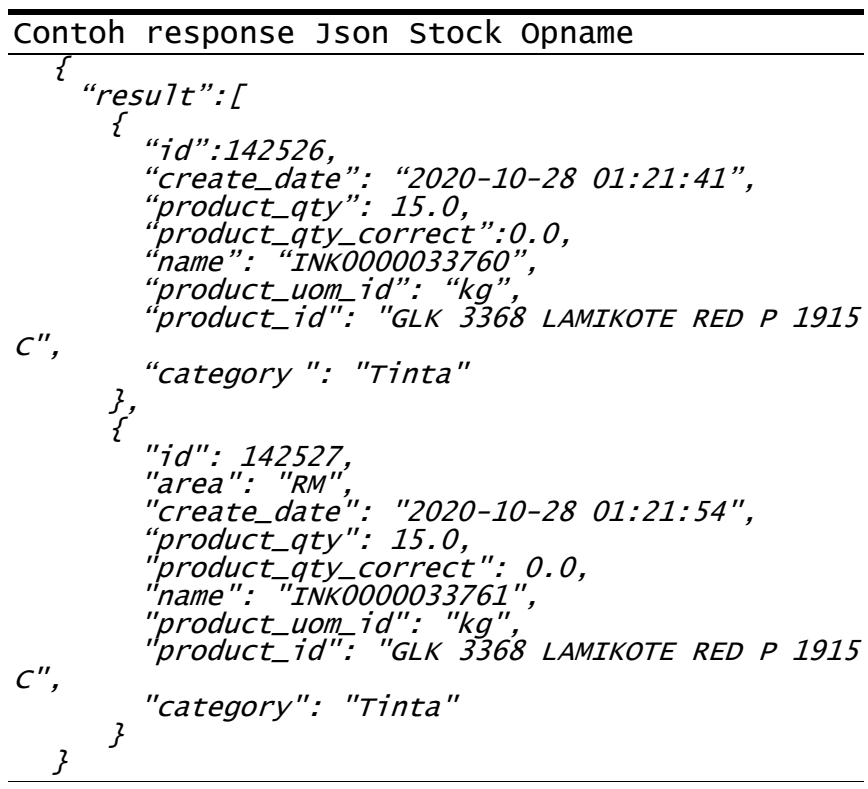

\section{H. Database Postgreql}

Dalam pembuatan aplikasi stock opname berbasis mobile ini database yang digunakan yaitu basis data postgresq. PostgreSQL adalah sistem manajemen basis data yang menekankan pada pemenuhan standar teknis dan felsibilitas data, database ini juga di distribusikan dengan lisensi yang bebas atau gratis. [17].

\section{HASIL DAN PEMBAHASAN}

Aplikasi stok opname ini difungsikan untuk menunjang kegiatan stok opname di PT. Modern Gravure Indonesia, yang sebelumnya menggunakan sistem pindai $q r$ code dengan menggunakan scanner $q r$ code dan 1 perangkat android. Untuk mengoptimalkan dan mengefisiensi pekerjaan dan waktu dalam kegiatan stok opname, maka dikembangkan sistem lama yang menjadi berbasis mobile, yaitu dengan satu perangkat dengan platform berbasis android dan iOS.

\section{A. Perancangan dan Evaluasi}


Pada bagian ini adalah penyusunan dan tahap analisis solusi untuk pengembangan sistem stock opname MGI, dalam perancangan aplikasi dibutuhkan pemodelan untuk dapat rincian dari fungsionalitas dan pemodelan yang dipakai adalah pemodelan UML (Unified Modelling Language) sebelum lanjut ke proses pengodean program.

Agar bisa mengilustrasikan fungsionalitas sistem yang akan kembangkan atau dibuat, maka dibutuhkan model dengan mengunakan diagram use case.

Use case ini untuk pengguna/user. Setelah user melakukan proses login, maka system akan menampilkan menu apa saja yang ada dan mereka bias akses di aplikasi stock opname MGI sesuai hak akses yang diberikan oleh admin sistem. Lalu akan menampilkan fungsionalitas seperti scan Qr code, melihat hasil scan Qr code, detail data, view data, list data. dapat dilihat pada gambar 3 .

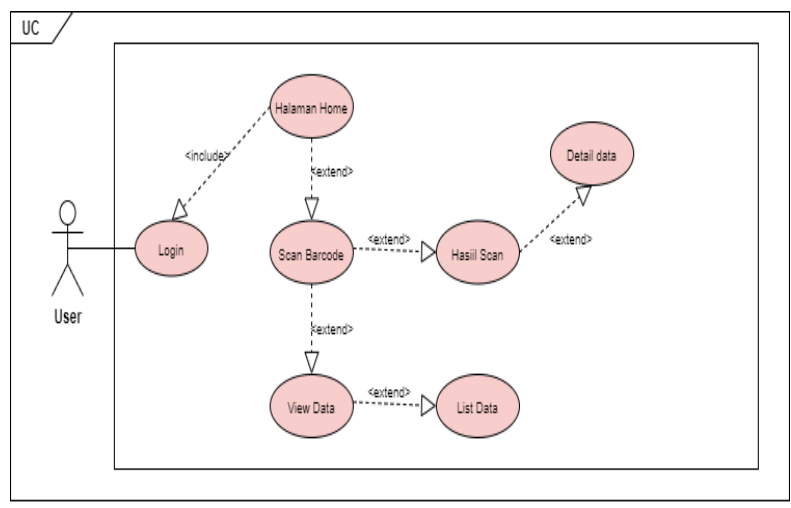

Gambar 5. Usec case user

Activity diagram ini adalah aktivitas pada saat user menjalankan aplikasi stok opname MGI kemudian sistem akan menampilkan halaman login yang selanjutnya user akan diarahkan untuk menginput username dan password lalu database akan memvalidasinya, jika user menginput daya yang benar maka akan langsung ke proses selanjutnya yaitu sistem akan menampilkan menu home, tetapi jika user salah dalam menginput data yang diminta maka user akan diminta menginput ulang data sampai berhasil di validasi oleh database. Saat sistem sudah menampilkan menu home, user akan memilih menu yang ada di halaman home tersebut dan sistem akan menampilkan rincian menu yang telah dipilih oleh user. dapat dilihat pada gambar 4.

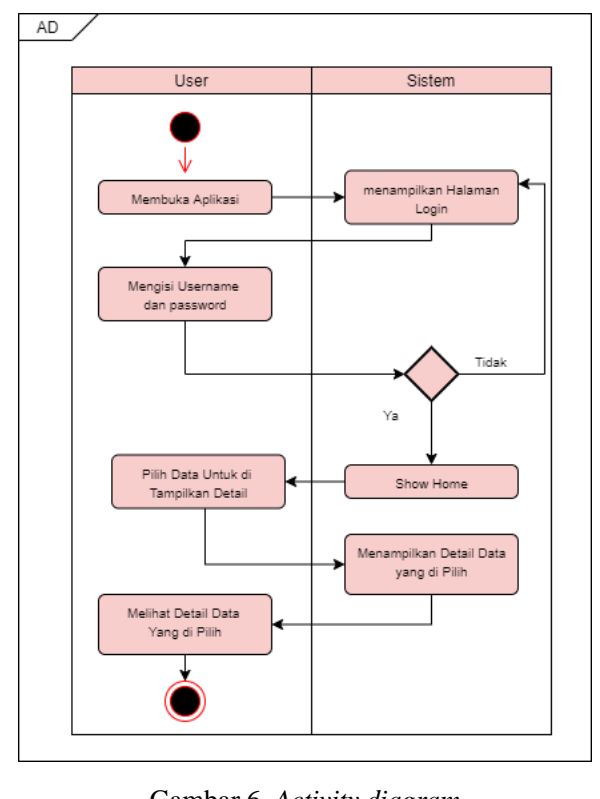

Gambar 6. Activity diagram

B. Implementasi Mobile Apps Sistem Stock Opnmae MGI

1) Tampilan splash screen

Menampilkan logo dari PT. Modern Gravure Indonesia diawal tampilan aplikasi ini dibuka akan menampilkan splash screen dimana tujuannya adalah sebagai identitas dari aplikasi i mobile untuk sistem stock opname juga memberikan informasi dari versi aplikasi yang sedang dijalankan.

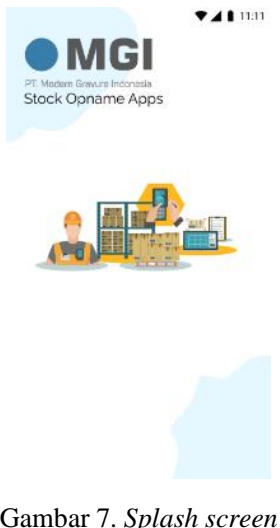

2) Tampilan login

Untuk memvalidasi user atau pengguna yang akan menggunakan aplikasi mobile ini sehingga mencegah terjadinya orang yang tidak berkepentingan menggunakan dan mengakses aplikasi ini. Jika bukan orang yang memiliki akses dari aplikasi ini dan akunnya sudah didaftarkan untuk mempunyai hak akses untuk menggunakan aplikasi mobile sistem stock opname MGI, untuk dapat mengakses aplikasi ini membutuhkan validasi dari data username/email dan password. 


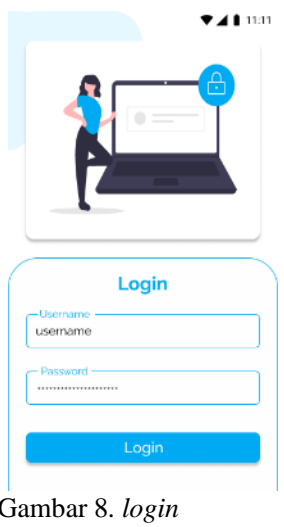

3) Tampilan home

Menampilkan deretan list menu dari aplikasi sistem stock opname berbasis mobile android dari menu yang ada yaitu main menu, view data, dan juga logout menu-menu ini diperlihatkan dalam bentuk gridview dan ada symbol atau logo untuk masingmasing menu agar dapat membedakan antara menu satu dengan menu yang lain pada aplikasi mobile sistem stock opname MGI.

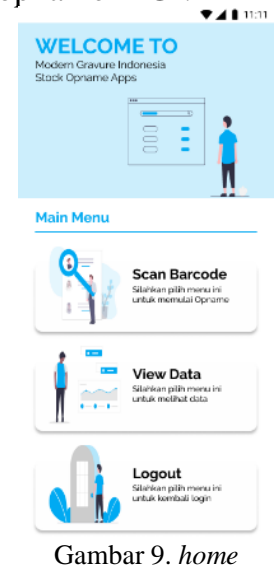

4) Tampilan scan $Q R$ Code

Digunakan untuk proses pembacaan Qr code yang ada pada label barang atau produk. Pembacaan Qr code aplikasi mobile sistem stock opname MGI ini dengan menggunakan fitur kamera yang ada di perangkat smartphone.

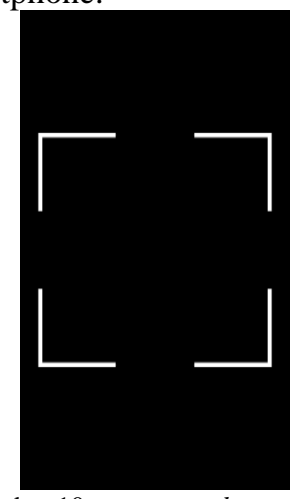

Gambar 10 scan qr code

5) Tampilan hasil scan QRcode

Digunakan sebagai hasil detail informasi barang yang terdapat di Qr code yang telah di scan menggunakan aplikasi mobile sistem stock opname
MGI. Seperti ID Qr code, jenis produknya, lokasi atau area produk, quantity dari produk tersebut hingga Qty KG dan dilengkapi dengan fitur pengeditan untuk mengatur jumlah quantity fisik yang real/sebenarnya.

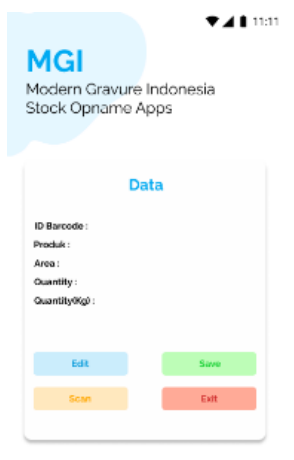

Gambar 11. Hasil scan

6) Tampilan view data

Digunakan untuk melihat keterangan detail waktu mulai dan waktu berakhirnya proses stock opname menggunakan aplikasi mobile sistem stock opname MGI, list data sendiri menampilkan hasil scan $\mathrm{Qr}$ code dari proses stock opname sesuai dengan pengaturan start date dan end date yang telah user atur.

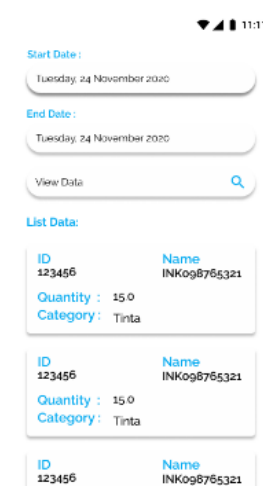

Gambar 12. View data

7) Tampilan detail data

Digunakan sebagai informasi lebih detail dari satu label $Q r$ code yang telah di scan di aplikasi stock opname MGI, sehingga dapat mengetahui ID produk, kategori produk, area produk, quantity produk, dan create date keterangan waktu dari kapan master produk di input ke sistem oleh administrator 


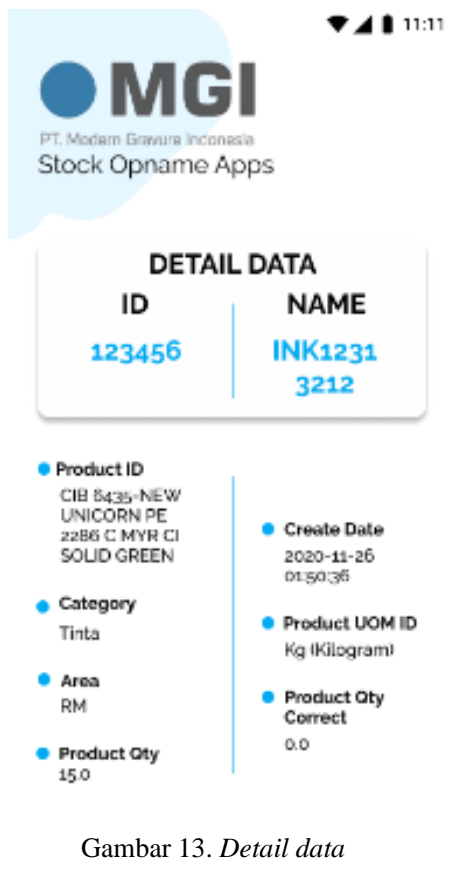

C. Hasil uji coba dengan metode black box

TABEL III. HASIL UJI COBA DENGAN METODE BLACK BOX

\begin{tabular}{|c|c|c|c|c|}
\hline No & Deskripsi & $\begin{array}{c}\text { Prosedur } \\
\text { Pengujian }\end{array}$ & $\begin{array}{c}\text { Output Yang } \\
\text { Diharapkan }\end{array}$ & Hasil \\
\hline 1 & $\begin{array}{l}\text { Menjalan } \\
\text { kan } \\
\text { aplikasi } \\
\text { untuk } \\
\text { pertama } \\
\text { kali }\end{array}$ & $\begin{array}{l}\text { Membuka } \\
\text { aplikasi yang } \\
\text { sudah } \\
\text { terinstall }\end{array}$ & $\begin{array}{l}\text { Menampilkan } \\
\text { splash screen } \\
\text { setiap } \\
\text { membuka } \\
\text { aplikasi }\end{array}$ & $\begin{array}{l}\text { Valid } \\
\text { (sesuai } \\
\text { dengan yang } \\
\text { diharapkan) }\end{array}$ \\
\hline 2 & $\begin{array}{l}\text { Melakuka } \\
\mathrm{n} \text { login }\end{array}$ & $\begin{array}{l}\text { Menginput } \\
\text { usernamei } \\
\text { dan } \\
\text { password }\end{array}$ & $\begin{array}{l}\text { Berhasil login } \\
\text { dan } \\
\text { menampilkan } \\
\text { halaman menu } \\
\text { home }\end{array}$ & $\begin{array}{l}\text { Valid } \\
\text { (sesuai } \\
\text { dengan yang } \\
\text { diharapkan) }\end{array}$ \\
\hline 3 & $\begin{array}{l}\text { Membuka } \\
\text { menu scan } \\
\text { Qr code } \\
\text { pada } \\
\text { halaman } \\
\text { home }\end{array}$ & $\begin{array}{l}\text { Mengklik } \\
\text { menu scan } \\
\text { Qr Code }\end{array}$ & $\begin{array}{l}\text { Menampilkan } \\
\text { tampilan scan } \\
\text { Qr code }\end{array}$ & $\begin{array}{l}\text { Valid } \\
\text { (sesuai } \\
\text { dengan yang } \\
\text { diharapkan) }\end{array}$ \\
\hline 4 & $\begin{array}{l}\text { Melakuka } \\
\mathrm{n} \text { proses } \\
\text { scan } Q r \\
\text { code }\end{array}$ & $\begin{array}{l}\text { Dilakukan } \\
\text { setelelah } Q r \\
\text { code di scan } \\
\text { dengan } \\
\text { terlebih } \\
\text { dahulu } \\
\text { membuka } \\
\text { menu scan } \\
\text { Qr code }\end{array}$ & $\begin{array}{l}\text { Manampilkan } \\
\text { data umum } \\
\text { dari hasil scan } \\
\text { Qr code }\end{array}$ & $\begin{array}{l}\text { Valid } \\
\text { (sesuai } \\
\text { dengan yang } \\
\text { diharapkan) }\end{array}$ \\
\hline 5 & $\begin{array}{l}\text { Mengedit } \\
\text { data dari } \\
\text { Qr code } \\
\text { yang telah } \\
\text { di scan di } \\
\text { halaman } \\
\text { hasil scan }\end{array}$ & $\begin{array}{l}\text { Mengklik } \\
\text { menu edit }\end{array}$ & $\begin{array}{l}\text { Menampilkan } \\
\text { menu edit data }\end{array}$ & $\begin{array}{l}\text { Valid } \\
\text { (sesuai } \\
\text { dengan yang } \\
\text { diharapkan) }\end{array}$ \\
\hline
\end{tabular}

\begin{tabular}{|l|l|l|l|l|}
\hline 7 & $\begin{array}{l}\text { Membuka } \\
\text { menu } \\
\text { view data } \\
\text { dari } \\
\text { halaman } \\
\text { home }\end{array}$ & $\begin{array}{l}\text { Mengklik } \\
\text { menu view } \\
\text { data }\end{array}$ & $\begin{array}{l}\text { Menampilkan } \\
\text { tampilan dari } \\
\text { view data }\end{array}$ & $\begin{array}{l}\text { Valid } \\
\text { (sesuai } \\
\text { dengan yang } \\
\text { diharapkan) }\end{array}$ \\
\hline 8 & $\begin{array}{l}\text { Mengiput } \\
\text { view data } \\
\text { untuk } \\
\text { melihat } \\
\text { proses } \\
\text { waktu } \\
\text { awal dan } \\
\text { batasan } \\
\text { waktu dari } \\
\text { proses } \\
\text { yang } \\
\text { sudah di } \\
\text { setting }\end{array}$ & $\begin{array}{l}\text { Menginput } \\
\text { start date } \\
\text { dan } \text { end date }\end{array}$ & $\begin{array}{l}\text { Menampilkan } \\
\text { list data pada } \\
\text { proses yang } \\
\text { sudah di } \\
\text { setting } \\
\text { sebelumnya }\end{array}$ & $\begin{array}{l}\text { Valid } \\
\text { (sesuai } \\
\text { dengan yang } \\
\text { diharapkan) }\end{array}$ \\
\hline 9 & $\begin{array}{l}\text { Melakuka } \\
\text { n logout }\end{array}$ & $\begin{array}{l}\text { Mengklik } \\
\text { menu logout }\end{array}$ & $\begin{array}{l}\text { Menampilkan } \\
\text { halaman login }\end{array}$ & $\begin{array}{l}\text { Valid } \\
\text { (sesuai } \\
\text { dengan yang } \\
\text { dii } \\
\text { harapkan) }\end{array}$ \\
\hline
\end{tabular}

Berdasarkan hasil pengujian sistem, keluaran dari aplikasi stock opname MGI berbasis mobile apps yang dirancang telah sesuai yang diharapkan, sehingga dapat disimpulkan bahwa aplikasi stock opname MGI berbasis mobile apps ini telah berhasil.

\section{Pembahasan}

Hasil akhir dari mobile apps stock opname MGI ini dapat lebih mempermudah petugas stock opname untuk bekerja meraih hasil yang optimal, peningkatan dan kelambatan proses stock opname dapat dilihat secara proses sistemnya sendiri karena proses dengan mobile apps ini lebih mempermudah petugas karena hanya membutuhkan satu perangkat saja sudah mencakup semua fitur dari sistem sebelumnya yang masih menggunakan tab, scanner, dan OTG. Dimana hal ini mengurangi beban biaya jika salah satu media atau perangkatnya rusak seperti rusaknya konektor antara tab dengan $\mathrm{otg}$.

Proses scan label Qr code ini dilakukan secara otomatis oleh 1 perangkat di masing-masing petugas atau user. User kemudian memasukan username dan password yang sudah didaftarkan di dalam database sebelumnya pada saat pertama kali dijalankan, selanjutnya akan dilakukan proses autentikasi, jika proses autentikasi berhasil, maka aplikasi akan menampilkan halaman home .

\section{KESIMPULAN}

Berdasarkan dari uraian diatas, maka dapat ditarik kesimpulan. Aplikasi stock opname berbasis mobile apps berjalan dengan efektif dan dapat meningkatkan performa dari sistem yang sebelumnya hal ini dibuktikan berdasarkan dari hasil pengujian menggunakan metode black box. Aplikasi ini berjalan dengan maksimal sesuai tujuan dan fungsinya.

\section{UCAPAN TERIMAKASIH}

PT. Modern Gravure Indonesia yang telah membantu dalam proses pengambilan data.

\section{REFERENSI}

[1] Niko Ramadhani, "Pengertian Serta Manfaat dari Melakukan Stock Opname Secara Rutin," Akseleran, 2020. 
https://www.akseleran.co.id/blog/stock-opname-

adalah/\#: :text=Stock opname adalah salah satu,di dalam gudang secara langsung. (accessed Nov. 23, 2020).

[2] Bivisyani Questibrilia, "Stock Opname: Pengertian, Manfaat, dan Tahap-Tahapnya," jojonomic, 2019. https://www.jojonomic.com/blog/stock-opname/ (accessed Nov. 23, 2020).

[3] Muhammad Fahruddin Yusuf, "PEMBUATAN APLIKASI MOBILE BERBASIS ANDROID SEBAGAI PENUNJANG KINERJA SALES," 2018.

[4] M. C. Mesah Tuahta Barus, Hindriyanto Dwi Purnomo, ST., MIT., Ph.D. Ramos Somya, S.Kom., "Perancangan Aplikasi Stock Opname Asset Berbasis Web ( Studi Kasus : PT Indomarco Prismatama )," no. 672012161, 2016.

[5] W. Pradani, A. Jamal, A. Triansyah, and A. Utami, "Pengembangan Sistem Informasi Perpustakaan Menggunakan Teknologi Google Web Toolkit (GWT)," J. Al-AZHAR Indones. SERI SAINS DAN Teknol., vol. 2, p. 96, 2013, doi: 10.36722/sst.v2i2.130.

[6] I. Subagio, A. Totok, P. Program, S. Diploma, P. Fkip, and U. Pontianak, "Stock Opname Koleksi Perpustakaan Sekolah Dasar Negeri 34 Pontianak Kota," J. Pendidik. dan Pembelajaran Khatulistiwa, vol. 9, no. 1, pp. 1-8, 2020, [Online]. Available: https://jurnal.untan.ac.id/index.php/jpdpb/article/view/38527.

[7] P. D. A. N. Pengabdian, P. Rahmawaty, M. Si, D. Respati, S Sumunar, and M. Si, "PROSIDING SEMINAR NASIONAL Prosiding Seminar Nasional,” vol. 2, no. January, pp. 978-979, 2012.

[8] B. Uddin, "Perancangan dan Implementasi Alat Rekam Data Stock Opname Berbasis Single Board Computer (SBC)," Petir, vol. 13, no. 2, pp. 240-254, 2020, doi: 10.33322/petir.v13i2.1109.

[9] H. Warsono, "Prevention at Margono Soekarjo Hospital Purwokerto- Indonesia," vol. 366, no. Icispe 2018, pp. 14-21, 2013.
Dengan Sisitem Periodik Dan Perpetual Berbasis Sia Terhadap Stock Opname Pada Perusahaan Dagang Di Pt Jasum Jaya," Accumulated J. (Accounting Manag. Res. Ed., vol. 1, no. 1, pp. 69-77, 2019, [Online]. Available: http://e-journal.potensiutama.ac.id/ojs/index.php/Accumulated/article/view/584.

[11] Ersandi Billah, "Pengertian dan Tahap Metode SDLC Waterfall," Medium.com, 2019. https://medium.com/@ersandibillah03/sdlcwaterfall-3a3c893be77b (accessed Nov. 25, 2020).

[12] Coccia, "Social and Administrative Sciences," J. Soc. Adm. Sci., vol. 2, no. 2, pp. 53-61, 2017.

[13] A. Putra, "Mengenal Flutter Mobile App SDK," Medium.com, 2017. https://medium.com/@putraxor/mengenal-flutter-mobileapp-sdk-9a5ca88e705b.

[14] M. Jones, J. Bradley, and N. Sakimura, "JSON web signature (JWS)," Internet Requests Comments, RFC, vol. 7515, 2015.

[15] K. Zheng and W. Jiang, "A token authentication solution for hadoop based on kerberos pre-authentication," in 2014 International Conference on Data Science and Advanced Analytics (DSAA), 2014, pp. 354-360.

[16] R. Gunawan and A. Rahmatulloh, "JSON Web Token (JWT) untuk Authentication pada Interoperabilitas Arsitektur berbasis RESTful Web Service," J. Edukasi dan Penelit. Inform., vol. 5, no. 1, p. 74, 2019, doi: 10.26418/jp.v5i1.27232.

[17] Eril, "Mengenal Lebih Lengkap Database PostgreSQL," Qwords, 2020. https://qwords.com/blog/database-adalah/. 